\section{Briginal inticlew.}

\section{REPOR'T ON SEVEN CASES OF TUBERCULO-} SIS TREATED WI'TH PARATALOID.

BY DRs. C. M. JONIS AND J. A. JEVFRIES.

Tre cases mentioned below were treated by us in co-operation with Dr. Thorndike in the House of the Good Samaritan during the months of February and March. 'The parataloid was from two lots, that of Dr. Beach and that of Dr. Shattuck. No difference was noted between the two either in action or strength. Below are the notes of the cases as extracted from the house records and special notes made by myself.

CAse I. H. R., December 25, 1890. Child, female, seven years old, born in New Brunswick. Family history negative. Four other children in fair health. A maternal aunt died of lung trouble. Nursed as an infant, but had poor health. Has had measles and whooping-cough. Present trouble began three years ago, and was followed by considerable loss of flesh. No night cries till four weeks ago, since then much pain.

Notes from the Children's Hospital, where she was first cared for, were as follows :

February 15, 1890. Little swelling about joint; $45^{\circ}$ permanent flexion; a few degrees of motiou. Right leg $22 \frac{1}{2}$ in., thigh $11 \frac{1}{2}$ in., calf $8 \frac{1}{2}$ in. ; left leg $22 \frac{3}{4}$ in., thigh 12 in., calf 9 in.

March 11, 1890. Abduction $7^{\circ}$; permanent flexion $25^{\circ}$. Right $\operatorname{leg} 21 \frac{1}{2}$ in., thigh $10 \frac{1}{2}$ in., calf 8 in; left leg $22 \frac{1}{4}$ in., thigh $12 \frac{1}{2}$ in., calf 9 in. Hip-splint applied.

From this time on to time of entrance into the Good Samaritan, records show a varying state, which it is not necessary to give in detail.

On admission, hip painful; extension hurts back. Put to bed on a frame, with traction in line of deformity; pain is severe if traction is let up for a moment. Right leg $22 \frac{1}{2}$ in., thigh 12 in., calf $7 \frac{1}{2}$ in ; left leg $23 \frac{1}{2}$ in., thigh $12 \frac{1}{2}$ in., calf 9 in.

December ]st. Looks poorly; hip very tender. 6th. Much better; hip much less tender. 14th. Fly. blister just over trochanter. 18th. Hip much less sensitive; abduction $10^{\circ}$.

January 15, 1891. Hip-splint applied and anchored with a weight. 25th. Abduction $15^{\circ}$; hip marked off in circles passing round the thigh over the joint. 26th. Hip more painful and sensitive; swollen about ten mm. aloug each of the circles. 29th. Child weighed $48 t$ pounds. Hip again marked off; upper circle measured $450 \mathrm{~mm}$, middle $370 \mathrm{~mm}$, lower $350 \mathrm{~mm}$., thigh $300 \mathrm{~mm}$. Swelling of a few days ago gone down. 30th. Parataloid (.0003) given at 9.30 A. M. Child bright all day. Slight rise of temperature in the evening. $31 \mathrm{st}$. Comfortable just as usual ; no tenderness in hip-joint. Circles measured $455 \mathrm{~mm}$., $373 \mathrm{~mm}$. and $350 \mathrm{~mm}$.

February 1st. Gave.006 of parataloid. No temperature change all day; at night hip less sensitive. Circles measured $456 \mathrm{~mm}$., $367 \mathrm{~mm}$. and $337 \mathrm{~mm}$. 2d. Hip less sensitive, and very slight rotation outward is now possible. Child bright. Circles $456 \mathrm{~mm}$., $370 \mathrm{~mm}$ and $334 \mathrm{~mm}$. No perceptible rise of tem. perature. 3d. Gave .001 of parataloid. Still more rotation in hip. Circles $356 \mathrm{~mm}$., $370 \mathrm{~mm}$. and 345 num. As yet no perceptible rise of temperature. 4 th. As yet no reaction. Circles $355 \mathrm{~mm}$., $378 \mathrm{~mm}$. and $345 \mathrm{~mm}$. 5th. Gave .0015 of parataloid, which was followed by no change. Circles $354 \mathrm{~mm}$., 374 mm. and $345 \mathrm{~mm}$. 6th. Condition the same. 7 th. Condition the same. Gave 002 of parataloid. 'Tem. perature rose slowly till $4 \mathrm{l}$. Mr, when it went up rapidly to $104.5^{\circ}$ at $7 \mathrm{P}$. M. Child bright up to $7 \mathrm{P}$. M., when a sharp reaction came on, the pulse being intermittent and then (rate 145). A drachm and a half of brandy was administered, and the child spent a grood night. During the period of high temperature the respiration was slightly increased in rate. 8th. Child bright; no local teuderness; slight motion both in abduction and adduction now possible. Circles $457 \mathrm{~mm}$., $373 \mathrm{~mm}$. and $345 \mathrm{~mm}$. 10th. Gave*.002; no reaction followed. Since commencement of treatment, to my mind, the child has lost color. There is slight swelling about joint, and motion is a trifle more free. 12th. Gave .0025 of parataloid; reaction followed, but less marked than on the $7 \mathrm{th}$. Circles 453 mm., $380 \mathrm{~mm}$. and $350 \mathrm{~mm}$. 13th. Circles $445 \mathrm{~mm}$., $375 \mathrm{~mm}$. and $350 \mathrm{~mm}$. 14th. Gave .003 of parataloid. No reaction followed. 15 th. Circles $450 \mathrm{~mm}$., $375 \mathrm{~mm}$. and $350 \mathrm{~mm}$. 17th. Gave .0035 ; a reaction (to temperature $103.5^{\circ}$, pulse 130 , at 10 P. Mr.) followed. In the evening she complained much of her back. 19th. Gave .0035 of parataloid, which was followed by slight reaction. 21st. Gave .0036 of parataloid, of Dr. Shattuck's lot; no reaction followed. 24th. Found temperature rising, so gave .0036 again; slight reaction followed. 26th. Gave .0042 ; there was no change in hip; no reaction. 28 th. Gave .0042 ; no reaction.

March 3d. Gave .0043; no reaction. 5th. Gave .0043 . On this date the use of parataloid was given up, as none of us could see any beneficial effect.

CaSE II. A. D., December 10, 1890. Female, twenty-five years old, single, born in Nova Scotia. Family history good. Never been sick until a year ago. Has had a cough for about a year, and more or less pain in left side. Lately has been short breathed. During the last nine months has lost about thirty pounds. Last June had two small hæmorrhages in one day. For the last two weeks has been in bed, during which time has had night sweats. No catamenia for a year.

Physical Examination. - Fairly well nourished. Weight 125 \% pounds; rather pale and flabby; pulse 84 ; heart normal. Lungs : Front, slight impairment of resonance at apices and on clavicles; slightly more marked on right ; respiration generally vesicular, with rather coarse râles over upper two-thirds of left and upper half of right; moderate concentration of voice under right clavicle. Back, dulness in supra-spinus fossw and one-half down scapulæ; respiration vesicula, with abundant râles as far as angle of scapula on both sides; increased vocal resonance in both supra spinus fossa, most on right. Urine acid; color normal ; specific gravity 1,023 ; no albumen.

January 25, 1891. Coughed considerable during day, but requires no medicine; sleeps well; general condition improved very much; weight $132 \frac{1}{4}$ pounds; râles over same area as before, but very few and scattered. 30th. Weight $133 \frac{8}{4}$ pouvds. Temperature has been running uniformly at about the normal.

February 1st. Gave .0003 parataloid; no rise of temperature. 2d. Temperature between $97^{\circ}$ and $98^{\circ}$ during day; no other change. 3d. Gave .0006 parataloid; temperature rose to normal during rest of 
day. 5th. Gave .001 parataloid; no reaction. 6th. Weight $133 \frac{1}{2}$ pounds. 7 th. Gave .0015 parataloid; no reaction, but a very scanty sputa (No. 3, of Gafkey's table). 8th. Sputa No. 2 contained one mast cell. 10th. Gave .0025 ; no reaction. Sputa before injection, No. 0 . 12th. Gavo .0035 parataloid. Sputa before injection, No. 2. So far no discomfort except slight tenderness and swelling at point of injection. 13th. Sputa No. 3; weight 137 pounds. 14th. Gave .0045 parataloid; no especial symptoms; sputa No. 2. 15th. No. 2. 16th. No. 1. 17th. Gave .0055 parataloid; no special symptoms; sputa No. 2, with small elastic fibres. So far can seo no difference, except that there is now a yellow, thick sputa in place of none. 18th. Temperature reached $100^{\circ}$ for the first time; no special symptoms; sputa No. 3, and one clump containing many hundred bacilli in a nest; catamenia for the first time in a year. 19th. Gave .0055 parataloid; sputa No. 4. 20th. Weight 136 pounds. 21 st. Gave .0066 parataloid; mild reaction ; temperature $101^{\circ}$ at night; pain over diseased portion of lung. 24th. Gave .0066 parataloid; sputa No. 2 ; no reaction. 26th. Gave .0078 parataloid; no reaction. 27th. Temperature subnormal, fluctuating. 28tb. Gave .009 parataloid.

March 2d. Temperature in morning $96^{\circ}$, rising to $100^{\circ}$ in afternoon. 3d. Gave .0102 parataloid; sputa No. 0. 5th. Gave .01 parataloid. 6th. Weight 134 pounds. 7th. Gave 0102 parataloid; temperature rose to $101^{\circ}$, with considerable pain and tenderuess over diseased portion of lung; increased pulse and respiration and aching in the limbs. 10th. Gave.01 parataloid; wo reaction. 12th. Gave .0108 parataloid; no reaction in temperature; pulse rose to 120 . 13th. Weight 135 pounds; apparently late reaction; temperature rising from $97^{\circ}$ in morning to $101^{\circ}$ at night. 14th. Gave .0108 parataloid; no reaction; 15th. Patient cough more than at entrance. Appetite has been poor for three or four weeks. Sleeps well. Chest front, resonance; right, dull in upper half; left, dull in upper third. Respiration generally vesicular; apex somewhat harsh; râles on both sides, as fur down as fourth rib, increased in numbers by cough; concentration of voice under both clavicles. Back, dull in supra-spinus fossa, one-third down scapula. 17th. Gave .0120 parataloid. 19th. Gave .0132 paratuloid; no reaction; sputa No. 3 ; stopped injection. For the last two weeks the temperature has fluctuated considerably, reaching $100^{\circ}$ or $101^{\circ}$ at night. The general state is not as good as when treatment was begun ; the appetite is poor, muscular power diminished. 20th. Weight 133 pounds. 24th. Sputa No. 2 . Patient was discharged at the end of the month certainly no better.

Case III. M. B., December 23, 1890. Female, single, twenty-two years old, born in Nova Scotia. Fumily history negative. Last February had measles followed by lung fever, and did not get out of doors until the first of May. Says the pneumonia was on the left side. Has worked from May up to a week ago. For the last two years has been losing strength, and has had a cough with some expectoration, chiefly in the morning. Has not lost much weight; no hæmorrhages. Catamenia rather irregular and scanty. When recovering from pneumonia had night sweats, but wone lately. Appetite good. Sleeps fairly. Bowels constipated.

Physical Examination. - Weight 92 pounds; tem- perature $99.6^{\circ}$; pulse 112 ; respiration 32 . Depres sions above clavicles most marked on the left. Chest, front: resonance impaired throughout left; most marked at apex ; right, good. Respiration (left) faint, broncho-vesicular at apex; vesicular below, with abundance of fine and medium moist rîles throughout. Concentration of voice at apex; right, vesicular without râles. Back: resonance impaired over upper half left and in right supra-spinus fossæ. Respiratiou (left) generally vesicular, with moist râles extending almost to base; right, vesicular without râles. Heart normal, except systolic souffle at pulmonic and aortic areas. Urine: color pale, slightly acid, specific gravity 1,009 ; no albumen.

January 30,1891 . Condition much improved. Weight 107 pounds. Little cough and no expectoration. 'Temperature about the normal.

February 1st. Gave .0003 of parataloid ; no reaction. 3d. Gave .0006 ; no reaction. 5th. Gave.001; no reaction. 6th. Weight 104 pounds. 7th. Gave .0015 ; no reaction. 10th. Gave .0025 ; reaction followed; temperature rose to $101^{\circ}$, with pain in the upper part of the chest and right arm. 12th. Gave .0025 ; no reaction. 14th. Gave .0035 ; no reaction. 17 th. Gave .0045 ; temperature rose to $102^{\circ}$ at 4 P. s., and then quickly fell off to normal. During the reaction there was considerable discomfort and pain in the chest and limbs. 19th. Gave .0045; no reaction. 20th. Weight 1061 pounds. 21st. Gave .0054 ; temperature rose to $100^{\circ}$. 24th. Gave.0054; no reaction. 26th. Gave .0066 ; no reaction; sputa for first time, one bacillus. 27th. Weight $107 \frac{1}{2}$ pounds. 28th. Gave .0078 ; no reaction.

March 3d. Gave .009; reaction; temperature rose from $96 \frac{1}{2}^{\circ}$ to $101^{\circ}$ with much pain and tenderness in the diseased portion of the lungs. 5th. Gave .009; no reaction. 6th. Weight $104 \frac{1}{2}$ pounds. 7th. Gave .0102 ; no reaction. 10th. Gave .0114; a trace of reaction; temperature to $100.4^{\circ}$. 12th. Gave .012 ; no reaction. 13th. Weight 107 pounds. 14th. Gave .0132 ; a trace of reaction; temperature to $100^{\circ}$. 15th. General condition good, eats well, sleeps well, very little cough in the morning, none at other times. Weighs more than ever before. Chest: front, resonance right, good; left, dulness extends from apex to cardiac dulness; resonance in axilla. Respiration: right, normal; left, a little prolonged just below clavicle; elsewhere vesicular with a few râles as far as base. Back : resonance on the right, good; left, dull half down scapula; good below. Respiration; right, normal; left, vesicular with a few râles in region of dulness. Slight concentration of voice. Voice-sound at apices. 16th. 'Temperature down to $96^{\circ}$. 17th. Gave .0144 ; trace of reaction; temperature to $100^{\circ}$. $19 \mathrm{ch}$. Gave .0156 ; no reaction. 20th. Weight 107 pounds. 21st. Gave .0168 ; trace of reaction. 24th. Gave .018 ; no reaction. Sputa No. 0. Treatment given up as we could see no beneficial effect, and she thought it was doing no good. 31st. Has continued to do well, weight increased, fair strength, almost no cough, and no expectoration.

The sputa in this case, what little there was, came, judging from the cells, chiefly from the fauces and trachea. An examination of the sputa showed enor. mous numbers of bacilli chiefly in clumps.

Case 1V. A. F., December 18, 1890. Female, married. Family history negative. Came to America when thirteen years old, and since has never been 
ill. Has had a cough for a year and a half, and for a year, a poor appetite. Is losing strength and has lost about 25 pounds. No hæmorrhage. Night sweats during the last three months, very profuse during the last three weeks. During the last year catamenia have been regular but very scanty. Four weeks ago was in the City Hospital on account of some uterine trouble.

Physical Examination. - Weight 115 pounds ; pulse 95 ; temperature $98.6^{\circ}$. Heart and abdomen normal. Lungs: right front, dulness as far as third rib, respiration feeble, broncho-vesicular with moist râles as far down as the edge of the fourth rib and a little lower after cough. Bronchophony over area of dulness; occasional dry râles. Left frout: respiration rather harsh with moist clicking on expiration along edge of sternum, otherwise normal. Back: Dull over upper half right, and impaired over whole of left; respiration, upper half, right, harsh tending to bronchial; moist râles as far as angle of scapula, and some concentration of voice; below normal. Respiration on left, upper half bronchial, bronchovesicular below, abundant moist râles throughout, increasing towards base and concentration of voice throughout.

Urine, acid; color normal; specific gravity 1,020; no albumen.

January 30,1891 . No change in chest. Weight $112 \frac{1}{2}$ pounds. 'Temperature running about normal.

February 1st. Gave .0003 of parataloid; no rise of temperature, but complained of pain in back and chest, and throat became a little sore. 3d. Gave .0006: same as before. 5th. Gave .001 ; no reaction; sputa No 8. 6th. Sputa No. 7; weight $112 \frac{1}{2}$ pounds. 7 th. Gave .0015 ; no reaction. 8th. Temperature rose at noon to $100^{\circ}$. 9th. Sputa No. 3. 10th. Gave.0025; no reaction; sputa No. 5 . 12th. Gave .0035 ; no reaction; sputa No. 0 , as found in two different trials, with two cover glasses each. Sputa is clearer, more glairy than at first, also increased, cough diminished. 13th. Sputa No. 8; weight 111 pounds; slight rise in temperature. 14th. Gave .0045 ; no reaction; sputa No. 4. 15th. 'Temperature rose to $101^{\circ}$; sputa No. 3. A number of small, red spots over chest and shoulders. 16th. Temperature rose same as yesterday; sputa No. 4. 17th. Gave .0055 ; followed by moderate rise of temperature; sputa No. 2; thick, yellow, but profuse. The nurse considers the patient stronger, but $I$ cannot see any difference except in her spirits. 18th. Sputa No. 2; no elastic fibres. 19th. Gave .0055 ; no reaction; sputa No. 5. 20th. Welght $112 \frac{1}{2}$ pounds. 21 st. Gave .0066; sharp rise of temperature to $102^{\circ}$, with general pain, occurred in the evening. 22d. Same reaction as yesterday. 24th. Gave .0066; slight reaction; sputa No. 5. 26th. Gave .0072; no reaction. 27th. Weight $112 \frac{8}{4}$ pounds. 28th. Gave.009; no reaction.

March 3d. Gave.0102; no distinct reaction. From this date on, the temperature became quite variable, rising to $102.5^{\circ}$ or falling to $95.5^{\circ}$ without any apparent cause. Sputa No. 6. 5th. Gave .0102; slight reaction. 7th. Gave .0102 . A sharp drop to $96^{\circ}$ followed by as rapid a rise of $5^{\circ}$. 'This associated with considerable discomfort and inability to take food. Looks badly. 9th. Appetite poor, general weakness, losing ambition, night sweats.

Physical Examination. - Front, dulness as before. Respiration: right upper third, harsh; expiration bronchial, with moist râles, not abundant, over region of dulness and to the base. Left, normal ; râles just above and below the clavicle. Back: left dulness as before. Respiration same. Râles on left over same area but not so abundant; right unchanged.

10th. Gave .01; no reaction. 14th. Gave .0114; a moderate reaction during the night, temperature rose to $102^{\circ}$. 17th. Gave .0114 ; no distinct reaction. 19th. Gave 0126 ; no distiuct reaction; sputa No. 4. 21st. Gave .0126 ; no distinct reaction, but temperature rose to $102^{\circ}$. 24th. Gave .0138; no reaction; sputa No. 5 . At this date treatment was stopped as we could see no benefit, and it was clear that patient's general state was by no means as good as when we began. Weight 111 pounds.

April 11th. Since last date temperature has returned to nearer the normal, the cough is more diffcult and the strength distinctly better. Lungs : front, slight increase of pitch and sense of resistance over right apex, respiration feeble to third rib and diminished to fifth. Back : left, dull over whole with more râles than before. Otherwise no change from last record.

Case V. M. D., October 10, 1890. Female, single, twenty-three years old. Family history negative. Has had pertussis, measles, scarlet fever and chickenpox. As a young girl, never has been very strong. but has had no serious sickness. Present illness began last winter when she had the grippe. Since then has had a cough. Five weeks ago had two hæmorrhages and lost considerable blood. Since June has lost nine pounds. During the last month cold night sweats two or three times a week. Catamenia scanty every five to six weeks. Almost constant headache, breath short especially after exercise, feet and hands swell, bowels regular, appetite poor, sleeps well.

Physical Examination. - Weight 111 pounds ; pulse 80 ; temperature $98.4^{\circ}$. Lungs: dulness throughout right side front and back; good resonance on the left. Respiration, right front, vesicular, expiration harsh and prolonged, abundant moist râles with bronchophony at apex ; left front normal. Right back : expiration in upper third, vesicular, elsewhere with scattered moist râles finer than in front, also bronchophony throughout; left back normal. Heart normal. Dulness over liver normal.

Urine high, acid; specific gravity 1,018 .

October 25th. Examination of front of chest shows no change.

February 13th. Weight $109 \frac{1}{2}$ pouuds. Left front normal ; right, dulness throughout, marked at apex. Respiration bronchial in upper third, harsh below; an abundance of medium and fine moist râles throughout. Left back normal; right, dull throughout, with bronchial respiration and rather course, moist rîles throughout. 'Temperature running from $97.5^{\circ}$ to $101^{\circ}$; sputa No. 2. 14th. Gave .005 of parataloid, followed by diffuse pain in bones and left lung, but no rise of temperature. 17th. Gave .001, followed by same symptoms as before. 19th. Gave .002; sputa No. 2. 20th. At 4, A. M. temperature rose abruptly from $98^{\circ}$ to $101.8^{\circ}$, the first definite reaction. 21st. Gave .003 ; same rise as before, but in the evening. Weight 110 pounds. 24th. Gave .003 ; temperature rose to $101.2^{\circ}$ in the evening; sputa Nos. $3,4.26$ th. Gave .0042 ; sharp rise to $101^{\circ}$ at night. 27 th. Same rise to-day. Weight $107 \frac{1}{2}$ pounds. 28th. Gavo .0042; temperature rose from normal to $103.5^{\circ}$ at $9 \mathrm{P}$. $\mathbf{M}$. 
with considerable discomfort and pain in the chest. Sputa No. 2.

March 3d. Gave .0042 . 5th. Gave .005 ; reaction followed. 7 th. .005 ; no reaction followed. Treatment given up as pationt was steadily going from bad to worse. 28 th. Physical symptoms about the same, dulness and bronchophouy more marked, and râles coarser in back than front. Sputa on the 24th, No. 3.

April 11th. General state distinctly worse, is clearly losing ground. Lungs the same, except that the right apex is resonant with a metallic click below clavicle.

Case VI. L. M., February 4, 1891. Female, married, twenty-eight years old. Sister died of phthisis. Measles and pertussis when a child. Cough began last July. Weight, 87 pounds. T'emperature, 98.5. Pulse 120. Respiration, 22.

February 13th. Weight, $89 \frac{1}{2}$ pounds, temperature showing evening rise to $101^{\circ}$ or $102^{\circ}$. Lungs : front, resonance good on right; on left, dull in upper half with tympanitic quality in places, fair elsewhere. Respiration : right, vesicular with a few scattered moist râles in upper fourth, normal below: left, bronchial, in places amphoric. Abundant moist râles half-way down chest. Bronchial voice and whisper marked in region of dulness. In lower third in sub-axillary re. gion, flat and respiration absent. Back: resonance right side normal ; left, dulness throughout, becoming flat towards base. A few râles in supra-spinous fossa right; left, respiration rather faiut, abundance of coarse, moist râles throughout except at base where respiration is scarcely heard. Sputa No. 8. 14th. Gave .0005 of parataloid at patient's request. No special rise of temperature or other symptom. $15 \mathrm{th}$. 'Temperature rose sharply from $98.4^{\circ}$ at 8 A. M., to $104.5^{\circ}$ at 1 p. M., then fell off. No marked pains. Sputa No. 8. 16 th. Same rise of temperature followed by a second rise in the evening. Sputa No. 2. 17th. Gave .001 . 'Temperature rose to $103^{\circ}$ in the evening, with much pain in the left side of the chest and limbs, sweating, face pinched, respiration rapid and shallow. Patient preferred to sit up, evidently had some orthopnœa. Au erythematous rash also appeared on the forearms. Sputa No. 3 with elastic fibres.

Temperature continued high from this date on for some weeks, rising from $98.4^{\circ}$ in the morning to $103^{\circ}$ or $104^{\circ}$ at noon, then dropping to rise again in the evening; thus tracing a letter M. During this period she lost strength rapidly, and the outlook did not seem very bright. On the 20th, patient weighed 89 pounds. For some time the number of bacilli in the sputa remained small, No. 2 or 3 , but later rose again to 7 and 8 . The temperature chart closely resembles that given of the prolonged roaction in leprosy.

Examination of lungs March 1st, was as follows : front, right, resonance fair; left, dull. Respiration, right, normal ; left, brouchial, in places amphoric, with moist râles throughout. Bronchophony on left side. Back : resonauce dull in the upper half of left side and the right supra-spinous fossæ, fair elsewhere; respiration, right, vesicular with moist râles in the supraspinous fossæ; left, vesicular, feeble with moist râles in the upper two-thirds. After the prolonged reaction had passed off, patient picked up, gained strength, a pound and three-quarters in weight, and was discharged much relieved April 1, 1891. This refers to the state following the use of parataloid, not that on entrance.
Case VII. I. J. November 21, 1890. Female, single, forty-five years old. Father died of phthisis. Fourteen years ago had scarlet fever; four years ago, diphtheria. Caught cold in July. Has had two small hæmorrhages and lost about twenty pounds, but the strength is still good. Weight, 80 pounds.

February 14 th. Weight, 81 pounds. Pulse thin. Temperature rising to $100^{\circ}$ or $101^{\circ}$ at night. Lungs : front, resonance impaired at apices; below fair, but high pitched. Respiration : right, harsh aud vesicular in upper third; normal below, without râles ; left, inspiration vesicular; expiration bronchial in upper half; moist râles throughout. Back: resonance on left; dull throughout right; high pitched in supra-spinous fossa. Respiration: right, somewhat harsh ; moist râles in the supra-spinous fossæ; none below; left, generally vesicular, with moist râles throughout. In the left supra-spinous fossa marked bronchial whisper. Sputa No. 3. Gave .0005 of paratoloid; no reaction. 18th. Gave .001 ; reaction to $104^{\circ}$ at $8 \mathrm{P}$. M. followed. Sputa No. 6.

From this time the high temperature occurred every afternoon; the appetite and strength failed rapidly; and besides the above it may be noted as common to all, that a certain amount of tenderness occurred at the point of injection; that during treatment the temperature rose higher than before or after, even when no "reactions" occurred; that after the first elation the appetite failed, and that no symptoms referable to the kidneys, other abdominal organs or nervous system occurred.

SUMMARY.

Case I. Showed no improvement, such changes as occurred being only such as were to be expected from rest in bed and the appliances used. In the first part of treatment slight swelling occurred which may or may not have been due to the parataloid.

CAsic II. Showed no improvement. Strength and appetite were impaired. Sputa with bacilli returned, and the progressive gain in weight was arrested.

CASE IIII. Bore the drug better than the others, continued to gain slightly in weight; developed cough, expectoration, and finally enormous numbers of tubercle bacilli. No improvement occurred in the lungs.

Case IV. Showed no improvement while under tratment, but lost strength. Since it was stopped the lungs have cleared up somewhat and the strength returned in part.

CASE V. Prompt and rapid failure which has continued.

Casx VI. Prompt and alarming increase in all the symptoms with slow recovery to former state.

Case VII. Prompt and alarming increase in all the symptoms, no improvement, rapid decline.

Tre following placard hangs in a Los Angeles store window :

Peppermint Ile for
Hed ake
Bellie “"
Tooth "

Chinese Grnecology. - A patient with prolapsed uterus lately consulted a Chinese doctor, when the learned man ordered a blister to the shaved crown of her head, in order to draw the prolapsed organ back again. 